\title{
Comparison of a Hemorrhoidectomy With Ultrasonic Scalpel Versus a Conventional Hemorrhoidectomy
}

\author{
Dae Ro Lim, Dae Hyun Cho, Joo Hyun Lee, Jae Hwan Moon \\ Department of Surgery, Armed Forces Daejeon Hospital, Daejeon, Korea
}

Purpose: A variety of instruments, including circular staplers, ultrasonic scalpels, lasers, and bipolar electrothermal devices, are currently used when performing a hemorrhoidectomy. This study compared outcomes between hemorrhoidectomies performed with an ultrasonic scalpel and conventional methods.

Methods: The study was a randomized prospective review of data available between May 2013 and December 2013, involving 50 patients who had undergone a hemorrhoidectomy for grade III or IV internal hemorrhoids. The hemorrhoidal pedicle was coagulated with an ultrasonic device in the ultrasonic scalpel group $(\mathrm{n}=25)$ and sutured with 3-0 vicryl material after excision in the conventional method group $(n=25)$.

Results: The patients' demographics, clinical characteristics, and lengths of hospital stay were similar in both groups. The mean ages of the conventional and the ultrasonic scalpel groups were, respectively, $20.8 \pm 1.6$ and $22.4 \pm 5.0$ years $(\mathrm{P}=$ $0.240)$. In comparison with the conventional method group, the ultrasonic scalpel group had a shorter operation time (P $<0.005$ ), less postoperative pain on the visual analogue scale score (for example, $\mathrm{P}=0.211$ on postoperative day 1 ), and less postoperative bleeding $(\mathrm{P}=0.034)$. No significant differences in postoperative complications were observed between the 2 groups.

Conclusion: A hemorrhoidectomy using an ultrasonic scalpel is an effective and safe procedure. The ultrasonic scalpel reduces the operation time, the postoperative blood loss, and the postoperative pain. Long-term follow-up with larger-scale studies is required to evaluate normal activity after a hemorrhoidectomy performed with an ultrasonic scalpel.

\section{Keywords: Hemorrhoidectomy; Ultrasonic scalpel; Conventional method}

\section{INTRODUCTION}

A hemorrhoidectomy is the standard treatment for patients with grade III or IV internal hemorrhoids [1]. The most effective hemorrhoidectomy methods are the Milligan-Morgan open hemorrhoidectomy and the Ferguson closed hemorrhoidectomy. These methods are similar and are recognized as traditional methods [2, 3 ]. However, although they may be the most effective treatment

Received: February 18, 2016 - Accepted: May 10, 2016

Correspondence to: Dae Ro Lim, M.D.

Department of Surgery, Armed Forces Daejeon Hospital, 27 Jaun-ro,

Yuseong-gu, Daejeon 34105, Korea

Tel: +82-42-878-4711, Fax: +82-32-621-6950

E-mail: bluecoffee79@gmail.com

(c) 2016 The Korean Society of Coloproctology

This is an open-access article distributed under the terms of the Creative Commons Attribution NonCommercial License (http://creativecommons.org/licenses/by-nc/4.0) which permits unrestricted noncommercial use, distribution, and reproduction in any medium, provided the original work is properly cited. for hemorrhoids, complications, such as postoperative bleeding, surgical-site anal pain, anal stenosis, and incontinence, can occur after the surgery. These complications increase the patient's hospitalization period, can delay the return to ordinary life and the workplace after surgery, and can increase the rate of revisits to the hospital [4]. In particular, postoperative pain and bleeding are experienced by many patients after undergoing a hemorrhoidectomy, and many patients complain of discomfort for a long time. As a result, various surgical equipment, surgical methods, and supportive therapies have been introduced to overcome the postoperative pain and bleeding.

In recent years, several pieces of surgical equipment have been developed due to advances in technology, and now hemorrhoidectomies are being performed with new devices, such as bipolar electrothermal devices, ultrasonic scalpels, and circular staplers. Hemorrhoidectomies performed with these devices have recently been reported to result in better pain relief and less bleeding postoperatively compared to hemorrhoidectomies performed using 
previous conventional surgical methods [5-7]. The ultrasonic scalpel uses ultrasonic vibration to cut tissue and automatically stop bleeding at the same time. A hemorrhoidectomy performed with an ultrasonic scalpel has several advantages, including less damage to tissues, better hemostasis, less stimulation to neuromuscular tissues, and local control of the surgical site, compared to a hemorrhoidectomy performed with surgical scissors or monopolar electric cautery $[5,6]$. The aim of the present study is to analyze and compare outcomes between hemorrhoidectomies performed with an ultrasonic scalpel and hemorrhoidectomies performed by using conventional methods, such as monopolar electric cautery.

\section{METHODS}

The participants were 50 patients who underwent a hemorrhoidectomy for grade III or IV internal hemorrhoids at Armed Forces Daejeon Hospital (single center) in Korea between May 2013 and December 2013. Twenty-five patients underwent a hemorrhoidectomy performed with monopolar electric cautery, which was defined as the conventional method. The other 25 patients underwent a hemorrhoidectomy performed with an ultrasonic scalpel. All of the patients' records were prospectively retrieved from a database. The participants were all male soldiers. Patients with liver cirrhosis, diabetes, hemorrhagic diseases, or HIV were excluded from the present study.

All patients underwent preoperative lab tests, chest X-rays, electrocardiography, and urinalysis and were admitted to the hospital the day before surgery. All patients took a glycerin enema the night before surger, and prophylactic antibiotics were injected before entrance to the surgical room. All patients had spinal anesthesia and were placed in the jackknife position. Tape was attached to both sides of the buttocks to expose the anus, and an anoscope was inserted into the anal canal in order to obtain the surgical field. The hemorrhoidal stems were lifted with forceps to separate them from the anal sphincter during surgery. In the present study, the conventional method performed was the Ferguson closed hemorrhoidectomy using monopolar electrocautery, and resection of hemorrhoidal tissue from the anal sphincter was performed with surgical scissors or a monopolar electrocautery device. Vicryl 3-0 surgical sutures were placed after the hemorrhoid mucosal resection. The hemorrhoidectomy performed using ultrasonic scalpel excised hemorrhoidal tissue and pedicle to the apex region without damaging the internal sphincter with the help of vascular forceps. The hemorrhoidal mucosa and coagulated blood vessels of the hemorrhoid were excised with an ultrasonic scalpel, and mucosal sutures were placed with 3-0 vicryl. A hemostat (Spongostan Anal, Johnson \& Johnson Medical Korea, Seoul, Korea) was inserted into the anal canal after surgery. For postoperative pain control, each patient was prescribed acetaminophen 2 tablets three times a day from the first day after surgery, and sitz baths were taken at least three times a day. We measured and recorded the resting pain and the postdefecation pain by using the visual analogue scale (VAS), as well as the amount of bleeding and urinary retention. We also noted any occurrence of an anal abscess or gangrene, an anal stricture, and fecal incontinence. The VAS score ranges from 0 , indicating no pain, to 10 , indicating severe pain. Major bleeding was defined as that requiring intensive treatment (including blood transfusion, reoperation) or close monitoring. Minor bleeding was defined that not needing monitoring with minimal bleeding after defecation.

All statistical analyses were performed using SAS ver. 9.1.3 (SAS Institute Inc., Cary, NC, USA) and IBM SPSS ver. 18.0 (IBM Co., Armonk, NY, USA). Categorical variables were analyzed using the chi-square or Fisher exact test, and continuous variables were analyzed using the Student $\mathrm{t}$-test or Mann-Whitney U rank test. We considered P-values of less than 0.05 to be statistically significant.

\section{RESULTS}

The mean ages of the participants were $20.8 \pm 1.6$ years in the conventional method group and $22.4 \pm 5.0$ years in the ultrasonic scalpel group. All of the patients were male. Their mean weights were $71.9 \pm 9.4 \mathrm{~kg}$ in the conventional method group and $69.2 \pm$ $9.4 \mathrm{~kg}$ in the ultrasonic scalpel group, and their mean heights were $175.9 \pm 6.1 \mathrm{~cm}$ and $174.1 \pm 4.2 \mathrm{~cm}$, respectively. The mean body mass indices were $23.2 \pm 2.3 \mathrm{~kg} / \mathrm{m}^{2}$ in the conventional method group and $22.8 \pm 2.7 \mathrm{~kg} / \mathrm{m}^{2}$ in the ultrasonic scalpel group. None of these differences between the two groups was statistically significant (Table 1).

The mean hospital stays were $25.7 \pm 15.0$ days in the conventional method group and $23.1 \pm 16.0$ days in the ultrasonic scalpel group, but this difference was not statistically significant; however, the mean operation times were $17.5 \pm 2.2$ minutes and $13.4 \pm 0.7$ minutes, respectively, and this difference was statistically significant with the operation time being significantly shorter in the ultrasonic scalpel group $(\mathrm{P}<0.05)$.

The postoperative resting pain scores were $6.5 \pm 1.7$ vs. $4.8 \pm 1.4$

Table 1. Patients' characteristics

\begin{tabular}{lccc}
\hline Characteristic & $\begin{array}{c}\text { Conventional method } \\
\text { group }(n=25)\end{array}$ & $\begin{array}{c}\text { Ultrasonic scalpel } \\
\text { group }(\mathrm{n}=25)\end{array}$ & P-value \\
\hline $\begin{array}{l}\text { Age }(\mathrm{yr}) \\
\text { Sex }\end{array}$ & $20.8 \pm 1.6(19-25)$ & $22.4 \pm 5.0(19-26)$ & 0.240 \\
$\quad$ Male & $25(100)$ & $25(100)$ & \\
Female & $0(0)$ & $0(0)$ & \\
Weight $(\mathrm{kg})$ & $71.9 \pm 9.4(60-91)$ & $69.2 \pm 9.4(56-90)$ & 0.624 \\
Height $(\mathrm{cm})$ & $175.9 \pm 6.1(163-189)$ & $174.1 \pm 4.2(164-185)$ & 0.324 \\
$\begin{array}{c}\text { Body mass index } \\
\left(\mathrm{kg} / \mathrm{m}^{2}\right)\end{array}$ & $23.2 \pm 2.3(16.0-39.1)$ & $22.8 \pm 2.7(20.8-29.4)$ & 0.620 \\
\hline
\end{tabular}

Values are presented as mean \pm standard deviation (range) or number (\%). 
Volume 32, Number 3, 2016

on postoperative day 3 (POD 3 ) and $1.5 \pm 1.2$ vs. $0.8 \pm 0.8$ on POD 14 in the conventional method group and the ultrasonic scalpel group, respectively, and these differences had statistical significance $(\mathrm{P}<0.05)$. However, PODs 1 and 7 , no statistically significant differences in postoperative resting pain were noted between the two groups (Table 2). Postoperative resting pain was observed to decrease gradually after peaking at 7 points and 6 points on POD 3 in the conventional method group and the ultrasonic scal-

Table 2. Comparison of the outcomes of the hemorrhoidectomies

\begin{tabular}{lccc}
\hline Variable & $\begin{array}{c}\text { Conventional method } \\
\text { group }(\mathrm{n}=25)\end{array}$ & $\begin{array}{c}\text { Ultrasonic scalpel } \\
\text { group }(\mathrm{n}=25)\end{array}$ & P-value \\
\hline Mean hospital stay (day) & $25.7 \pm 15.0$ & $23.1 \pm 16.0$ & 0.726 \\
Operation times (min) & $17.5 \pm 2.2$ & $13.4 \pm 0.7$ & $<0.05$ \\
$\begin{array}{l}\text { Postoperative resting } \\
\text { pain (VAS scores) }\end{array}$ & & & \\
Day 1 & $6.8 \pm 1.4$ & $5.4 \pm 0.7$ & 0.211 \\
Day 3 & $6.5 \pm 1.7$ & $4.8 \pm 1.4$ & $<0.05$ \\
Day 7 & $5.5 \pm 1.2$ & $4.1 \pm 0.6$ & 0.078 \\
Day 14 & $1.5 \pm 1.2$ & $0.8 \pm 0.8$ & $<0.05$ \\
Post defecation pain & & & \\
(VAS score) & & & \\
Day 3 & $6.5 \pm 1.0$ & $6.2 \pm 1.1$ & 0.734 \\
Day 7 & $5.6 \pm 0.8$ & $5.9 \pm 1.1$ & 0.365 \\
Day 14 & $2.5 \pm 0.9$ & $2.5 \pm 1.0$ & 1.000 \\
Day 21 & $2.1 \pm 1.0$ & $1.1 \pm 0.9$ & 0.581 \\
Day 28 & $0.6 \pm 0.7$ & $0.3 \pm 0.5$ & 0.081 \\
\hline
\end{tabular}

Values are presented as mean \pm standard deviation.

VAS, visual analogue scale.

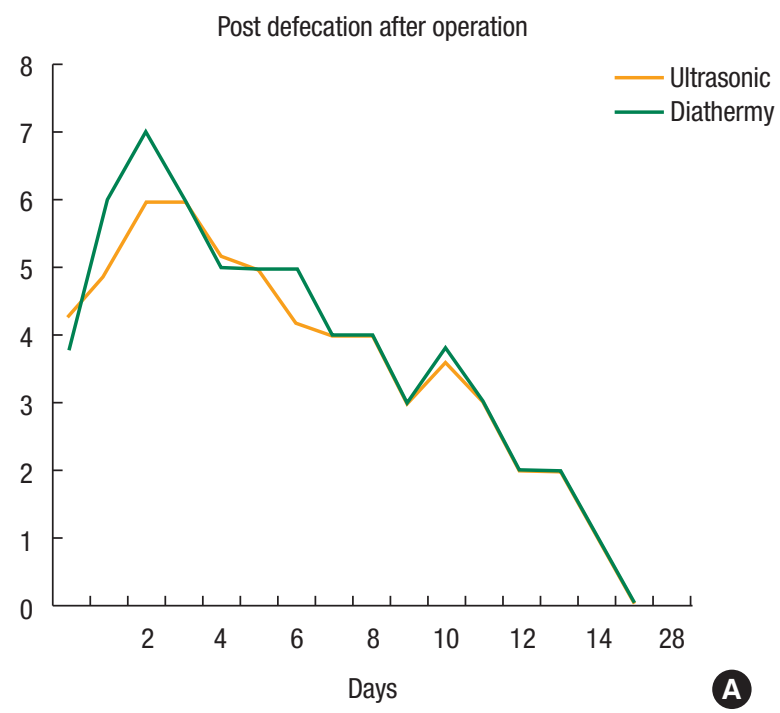

pel group, respectively, and showed a similar progression to complete resolution by POD 21 in both groups. However, the pain scores were 2-3 points lower from POD 4 to POD 8 in the ultrasonic scalpel group than they were in the conventional method group. In addition, the pain scores between POD 14 and POD 21 showed that the period until complete resolution was shorter in the ultrasonic scalpel group than it was in the conventional method group (22 days vs. 18 days, respectively) (Fig. 1). No statistically significant differences in pain patterns between the 2 groups were noted for postdefecation pain, which gradually decreased after reaching its highest level on POD 3 until being completely resolved by POD 21.

Table 3. Complications from the hemorrhoidectomies

\begin{tabular}{lccc}
\hline Complication & $\begin{array}{c}\text { Conventional method } \\
\text { group }(n=25)\end{array}$ & $\begin{array}{c}\text { Ultrasonic scalpel } \\
\text { group }(n=25)\end{array}$ & P-value \\
\hline Bleeding & & & 0.034 \\
$\quad$ Major & $2(8)$ & $0(0)$ & \\
$\quad$ Minor & $6(24)$ & $3(12)$ & \\
Delayed discharge & $2(8)$ & $2(8)$ & NS \\
$\begin{array}{l}\text { Incomplete wound healing } \\
\text { (at 4 weeks) }\end{array}$ & $1(4)$ & $1(4)$ & \\
Wound breakdown & $2(8)$ & $2(8)$ & \\
Urinary retention & $0(0)$ & $0(0)$ & NS \\
Anal fissure & $1(4)$ & $0(0)$ & \\
Anal stenosis & $0(0)$ & $0(0)$ & \\
Incontinence & $0(0)$ & $0(0)$ & \\
\hline
\end{tabular}

Values are presented as number (\%).

NS, not significant.

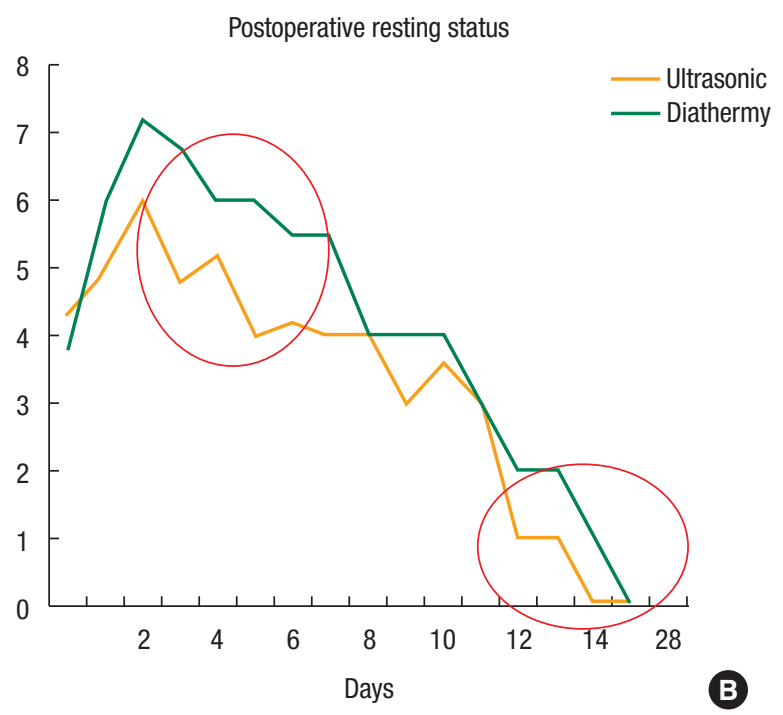

Fig. 1. Visual analogue scale pain scores for pain after defecation (A) and for resting status pain (B) from postoperative day 0 to 22 after hemorrhoidectomy. 
In the conventional method group, 2 patients (8\%) had major bleeding after surgery that required blood transfusion or repeat operation on POD 1, and 6 patients (24\%) had minor bleeding on POD 1. Conversely, in the ultrasonic scalpel group no major bleeding occurred after surgery, but minor bleeding did occur in 3 patients $(12 \%)(\mathrm{P}<0.034)$. No significant differences in complications were noted between the 2 groups. The complications reported were delayed discharge ( 2 in each group), incomplete wound-healing ( 1 in each group), and wound breakdown ( 2 in each group). No urinary retention, anal stenosis, or incontinence was noted in either group (Table 3).

\section{DISCUSSION}

The exact prevalence of hemorrhoids in Korea is not known, but according to a National Health Insurance Corporation report in 2012, among the major surgeries conducted in Korea in 2011, the hemorrhoidectomy accounted for the second-largest number of cases (226,409 cases/yr), after cataract surgery [8]. This shows that a significant number of patients, at a rate of 445 per 100,000 individuals, have needed treatment for hemorrhoids. Traditional hemorrhoidectomy techniques, including a Milligan-Morgan open hemorrhoidectomy and a Ferguson closed hemorrhoidectomy, are known to be very effective and appropriate treatments for grades III-IV internal hemorrhoids. However, these traditional surgical methods are characteristically accompanied by complications such as postoperative pain and bleeding [9]. Recently, hemorrhoidectomies done with circular staplers and other newly developed equipment have been reported to result in less postoperative pain, less bleeding, rarer complications (urinary retention, anal stenosis), shorter operation times, and shorter hospital stays [10-13].

A hemorrhoidectomy with a circular stapler is performed to excise a complete ring of mucosa, including the hemorrhoidal tissue, above the dentate line $[13,14]$. However, this procedure is limited to removing prolapsed hemorrhoidal tissues of the anal verge or skin tags [15]. In addition, the cost of performing a hemorrhoidectomy with a circular stapler is high, and the method often leads to complications such as postoperative bleeding, rupture of the anastomosis site, pelvic sepsis, anastomotic stricture, and rectovaginal fistulae [16].

The LigaSure and harmonic scalpels are newly developed ultrasonic scalpel instruments with automatic vessel-sealing systems. These instruments contain a bipolar, electrothermal, hemostatic device that use radio-frequencies and pressure to ensure complete cutting and coagulation of vessels up to $7 \mathrm{~mm}$ in diameter, with minimal surrounding thermal spread $(<2 \mathrm{~mm})$ and limited tissue-charring [17]. For a hemorrhoidectomy performed with an ultrasonic scalpel, intraoperative bleeding may be minimized, and the visibility of the surgical field is better. Performing resection and hemostasis at the same time reduces the operation time and complications, such as postoperative bleeding, pain, and infec- tion, by reducing the damage to the surrounding mucosal tissue. In contrast, for a hemorrhoidectomy performed with conventional methods, the surrounding mucosal tissues and blood vessels can be damaged during resection of the hemorrhoidal tissue, and the time to hemostasis of the blood vessels and tissues may cause increases in both the operation times and the possibility of postoperative bleeding. Furthermore, several previous studies have reported that the use of the ultrasonic scalpel results in significantly shorter operation times and less postoperative bleeding when compared with a conventional hemorrhoidectomy $[5,6,18$, 19]. In the present study's ultrasonic scalpel group, no patient experienced major bleeding and 3 patients (12\%) experienced minor bleeding; however, in the conventional method group, 2 patients (8\%) experienced major bleeding and 6 (24\%) experienced minor bleeding. Most patients with complications were successfully treated with conservative management. Also, the operation times were shorter in the ultrasonic scalpel group than they were in the conventional method group $(17.5 \pm 2.2$ minutes vs. $13.4 \pm$ 0.7 minutes, respectively; $\mathrm{P}<0.05)$.

One of the causes of postoperative pain after a hemorrhoidectomy is excessive damage to the sensitive perianal skin or tissue, and sometimes pain occurs due to stress or strain at the site of the mucosal sutures [4]. A number of ways have been attempted to relieve pain after a hemorrhoidectomy. For example, Ala et al. [20] reported that cholestyramine ointment was effective against postoperative pain after a hemorrhoidectomy; the ointment group experienced less pain 12 and 48 hours after surgery than the control group did, and their pain completely disappeared 2 weeks later. Other effective treatments for the relief of postoperative pain, including preoperative lactulose [21], postoperative metronidazole [22], a left lateral anal sphincterectomy with hemorrhoidectomy $[5,23]$, and botulinum injections, have been reported [24]. However, these methods have individual variations in pain-relief effectiveness and there are no general effects. The ultrasonic scalpel minimizes the damage to surrounding tissues, and suture closure is not required for hemostasis during the hemorrhoidectomy. This limited spread reduces anal spasms, allows for a bloodless hemorrhoidectomy, and can result in reduced postoperative pain and faster wound-healing. Previous studies have reported less immediate postoperative pain and less pain 24 hours and 7 days after surgery in ultrasonic scalpel groups compared with conventional hemorrhoidectomy groups. A shorter time to return to ordinary life and shorter hospital stays have also been reported $[5,6$, $18,19,25]$. In the present study, less pain on POD 4 and POD 8 was found in the ultrasonic scalpel group; however, no significant differences in immediate postoperative pain, pain 24 hours after surgery, and post-defecation pain were noted.

While the average hospital stay after a hemorrhoidectomy is 3-4 days in Korea in general, the average stay was very long in the present study, at 24.4 days ( $25.7 \pm 15.0$ days vs. $23.1 \pm 16.0$ days in the conventional method group and the ultrasonic scalpel group, respectively). The reason for this longer stay is the peculiarities of 
military hospitals. All patients in the present study were soldiers, who immediately had to return to military service and take part in military activities after discharge, so they would not have been able to take care of postoperative management such as resting, sitz baths, and medications after discharge. For that reason, these patients were not discharged from the hospital until postoperative symptoms, such as pain or anal discharge, had disappeared completely. Therefore, a major limitation of the present study was the ability to provide values for the time of return to ordinary life and for the length of hospital stay that could be compared to the corresponding values in other studies done involving patient in nonmilitary hospitals.

However, the present study was able to measure the progress of postoperative pain (during rest and postdefecation) for a much longer period than in the average hospital stay. Postoperative resting pain decreased gradually after peaking at 7 points and 6 points on POD 3 in the conventional method group and the ultrasonic scalpel group, respectively, and the patterns of progress until the pain had completely disappeared by POD 21 in the 2 groups were similar. The patterns of progress in reducing postdefecation pain were also similar between the 2 groups. However, although this was a small-scale study, the pain scores were $2-3$ points lower from POD 4 to POD 8 in the ultrasonic scalpel group. In addition, the pain scores between POD 14 and POD 21 showed that the period until complete disappearance of pain was shorter in the ultrasonic scalpel group compared with the conventional method group (22 days vs. 18 days). Altomare et al. [26] reported in 2008 that pain scores 12 hours after surgery, postdefecation, and on POD 3 and POD 7 were lower in 274 patients who had undergone a hemorrhoidectomy with LigaSure and that less medication was used for pain relief on POD 3 and POD 4. Also, no severe complications occurred in either the ultra-sonic scalpel group or the conventional method group, and most patients with complications responded to conservative manage-ment.

In conclusion, a hemorrhoidectomy performed with an ultrasonic scalpel is a relatively safe and easy surgical procedure without serious complications. The use of an ultrasonic scalpel reduces the operation time, postoperative blood loss, and postoperative pain. Thus, a hemorrhoidectomy performed using an ultrasonic scalpel is recommended as an alternative approach to existing conventional hemorrhoidectomy techniques.

\section{CONFLICT OF INTEREST}

No potential conflict of interest relevant to this article was reported.

\section{REFERENCES}

1. MacRae HM, McLeod RS. Comparison of hemorrhoidal treatment modalities. A meta-analysis. Dis Colon Rectum 1995;38:
687-94.

2. Milligan ET, Morgan CN, Jones LE, Office R. Surgical anatomy of the anal canal, and the operative treatment of hæmorrhoids. Lancet 1937;230:1119-24.

3. Ferguson JA, Heaton JR. Closed hemorrhoidectomy. Dis Colon Rectum 1959;2:176-9.

4. Goligher JC, Graham NG, Clark CG, De Dombal FT, Giles G. The value of stretching the anal sphincters in the relief of posthaemorrhoidectomy pain. Br J Surg 1969;56:859-61.

5. Jayne DG, Botterill I, Ambrose NS, Brennan TG, Guillou PJ, O'Riordain DS. Randomized clinical trial of Ligasure versus conventional diathermy for day-case haemorrhoidectomy. Br J Surg 2002;89:428-32.

6. Bulus H, Tas A, Coskun A, Kucukazman M. Evaluation of two hemorrhoidectomy techniques: harmonic scalpel and Ferguson's with electrocautery. Asian J Surg 2014;37:20-3.

7. Jayaraman S, Colquhoun PH, Malthaner RA. Stapled versus conventional surgery for hemorrhoids. Cochrane Database Syst Rev 2006;(4):CD005393.

8. National Health Insurance Service. 2011 major surgery statistics [Internet]. Wonju: National Health Insurance Service; c2011 [cited 2015 May 10]. Available from: www.nhis.or.kr/bbs7/boards/ B0079/6322.

9. Chen JS, You JF. Current status of surgical treatment for hemorrhoids: systematic review and meta-analysis. Chang Gung Med J 2010;33:488-500.

10. Sgourakis G, Sotiropoulos GC, Dedemadi G, Radtke A, Papanikolaou I, Christofides T, et al. Stapled versus Ferguson hemorrhoidectomy: is there any evidence-based information? Int J Colorectal Dis 2008;23:825-32.

11. Gravie JF, Lehur PA, Huten N, Papillon M, Fantoli M, Descottes B, et al. Stapled hemorrhoidopexy versus milligan-morgan hemorrhoidectomy: a prospective, randomized, multicenter trial with 2-year postoperative follow up. Ann Surg 2005;242:29-35.

12. Ascanelli S, Gregorio C, Tonini G, Baccarini M, Azzena G. Long stapled haemorrhoidectomy versus Milligan-Morgan procedure: short- and long-term results of a randomised, controlled, prospective trial. Chir Ital 2005;57:439-47.

13. Hetzer FH, Demartines N, Handschin AE, Clavien PA. Stapled vs excision hemorrhoidectomy: long-term results of a prospective randomized trial. Arch Surg 2002;137:337-40.

14. Longo A. Treatment of haemorrhoid disease by reduction of mucosa and haemorrhoidal prolapse with a circular-suturing device: a new procedure. In: Proceedings of the Sixth World Congress of Endoscopic Surgery; 1998 Jun 3-6; Rome, Italy. Bologna: Monduzzi Editore, International Proceedings Division; 1998. p. 77784.

15. Engel AF, Eijsbouts QA. Haemorrhoidectomy: painful choice. Lancet 2000;355:2253-4.

16. Ravo B, Amato A, Bianco V, Boccasanta P, Bottini C, Carriero A, et al. Complications after stapled hemorrhoidectomy: can they be prevented? Tech Coloproctol 2002;6:83-8. 
17. Sayfan J, Becker A, Koltun L. Sutureless closed hemorrhoidectomy: a new technique. Ann Surg 2001;234:21-4.

18. Gentile M, De Rosa M, Carbone G, Pilone V, Mosella F, Forestieri P. LigaSure haemorrhoidectomy versus conventional diathermy for IV-degree haemorrhoids: is it the treatment of choice? A randomized, clinical trial. ISRN Gastroenterol 2011;2011:467258.

19. Milito G, Cadeddu F, Muzi MG, Nigro C, Farinon AM. Haemorrhoidectomy with Ligasure vs conventional excisional techniques: meta-analysis of randomized controlled trials. Colorectal Dis 2010;12:85-93.

20. Ala S, Eshghi F, Enayatifard R, Fazel P, Rezaei B, Hadianamrei R. Efficacy of cholestyramine ointment in reduction of postoperative pain and pain during defecation after open hemorrhoidectomy: results of a prospective, single-center, randomized, doubleblind, placebo-controlled trial. World J Surg 2013;37:657-62.

21. London NJ, Bramley PD, Windle R. Effect of four days of preoperative lactulose on posthaemorrhoidectomy pain: results of placebo controlled trial. Br Med J (Clin Res Ed) 1987;295:363-4.

22. Carapeti EA, Kamm MA, McDonald PJ, Phillips RK. Double- blind randomised controlled trial of effect of metronidazole on pain after day-case haemorrhoidectomy. Lancet 1998;351:169-72.

23. Galizia G, Lieto E, Castellano P, Pelosio L, Imperatore V, Pigantelli C. Lateral internal sphincterotomy together with haemorrhoidectomy for treatment of haemorrhoids: a randomised prospective study. Eur J Surg 2000;166:223-8.

24. Patti R, Almasio PL, Muggeo VM, Buscemi S, Arcara M, Matranga S, et al. Improvement of wound healing after hemorrhoidectomy: a double-blind, randomized study of botulinum toxin injection. Dis Colon Rectum 2005;48:2173-9.

25. Khan S, Pawlak SE, Eggenberger JC, Lee CS, Szilagy EJ, Wu JS, et al. Surgical treatment of hemorrhoids: prospective, randomized trial comparing closed excisional hemorrhoidectomy and the Harmonic Scalpel technique of excisional hemorrhoidectomy. Dis Colon Rectum 2001;44:845-9.

26. Altomare DF, Milito G, Andreoli R, Arcanà F, Tricomi N, Salafia C, et al. Ligasure Precise vs. conventional diathermy for MilliganMorgan hemorrhoidectomy: a prospective, randomized, multicenter trial. Dis Colon Rectum 2008;51:514-9. 